\title{
Comparative Morphometrical Nuclear Investigation Of The Peripheral Region In Basaloid Cell Cutaneous Neoplasms
}

\author{
O.D. Ribeiro,* M.A. Guzmán-Silva,* and M.C. Rochael* \\ * Department of Pathology, Universidade Federal Fluminense, Niteroi, RJ, Brazil, 24030-210
}

The basal cell carcinoma (BCC) is the most frequent neoplasia in populations of white genetic background and in spite of the infrequent metastasis, destructive and invasive behavior cannot be despised [1]. Other benign neoplasms also present morphologic characteristics similar to the $\mathrm{BCC}$, among them neoplasms of follicular origin as the trichoblastoma (TB) and the trichoepithelioma (TE). Both are part of the differential diagnoses for this tumor [1].

To evaluate the possibilities to differentiate these neoplasms, we performed an morphometrycal study of 50 lesions. Thirty were BCC - 10 of each subtype, sclerodermiform (Scl), nodular (Nod), and superficial (Sup) - 10 trichoblastomas, and 10 trichoepiteliomas. From each one of the 50 selected lesions, 10 images of peripheral fields of the tumor nest were digitalized, being considered as cells of the periphery those that were in direct contact with the stroma. Digitalization was performed through a JVC camera, TK 1270 model, coupled to a ZEISS optical microscope, under x400 amplification. The nuclear parameters were analyzed by a macro created for this purpose (Fig. 1, Table 1 \& 2) in the Kontron Elektronic KS300 system. The nuclear area, perimeter, minimum diameter (MIND), maximum diameter (MAXD), elliptic factor (EF), and regularity factor (RF) were obtained. The mean value and the standard deviation (Table 3) of each parameter were calculated. The results were submitted to the Mann-Whitney U non-parametric test using the program SPSS 9.0 and the values with $\mathrm{P} \leq 0.05$ were considered significant. With the statistical analysis of the mean values we verified the existence of significant difference in 21 comparisons. Nuclear area and perimeter, and minimum diameter were the parameters that most frequently showed statistical differences among the investigated neoplasms. Those values for the trichoepithelioma were lower than the sclerodermiform, the nodular, and the superficial BCCs. Also, those values for the nodular BCC were higher than the superficial one. In the same way, the values of the standard deviation of each of the morphometrical parameter were analyzed comparing the peripheral region of basaloid cell cutaneous neoplasms, once those values would serve as indicative of the nuclear pleomorphism [2]. With this approach we found significant difference in 19 comparisons, being the nuclear area and the minimum and maximum diameter the most frequent parameters with differences. Those parameters, together with nuclear perimeter, allow to distinguish the sclerodermiform BCC from the trichoblastoma, as well as the nodular BCC form the trichoblastoma and the trichoepithelioma.

We conclude that comparative morphometrical nuclear investigation in the peripheral region between basaloid cell cutaneous neoplasms allows to specially distinguish the trichoblastoma and the trichoepithelioma from the different subtypes of BCC due to a lower nuclei size and pleomorfism of the benign forms of basaloid cell cutaneous neoplasms.

\section{References}

[1] R.L. Barnhill, Textbook of Dermatophatology, McGraw-Hill Companies, USA, 1998.

[2] I.F. Orengo et al., J. Am. Acad. Dermatol., 37(3) (1997) 395.

[3] This research was supported by the CNPq - Conselho Nacional de Pesquisa e Desenvolvimento. 

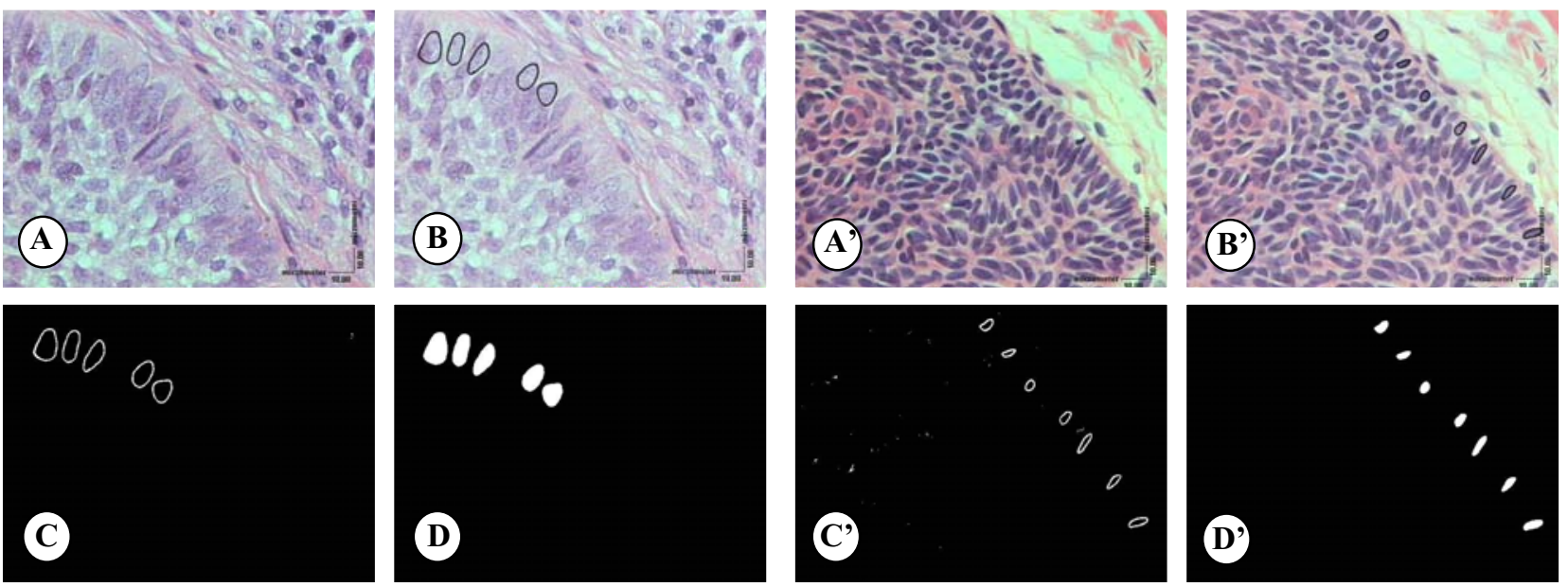

FIGURE 1. Sequence of images of the peripheral area of a nodular basal cell carcinoma (left) and of a trichoepithelioma (right) during the execution of the macro for analysis of the preset nuclear parameters in the KS300 version 2.0 Kontron system. A \& A' - original image, HE; B \& B' - image with the nuclei delineated manually; C \& C' - semiautomatic binary image; D \& D' - binary image with retreat of black pixels inside of the nuclei and of white pixels out of the nuclei that corresponds to the final image submitted to the automatic measurement.

\begin{tabular}{|c|c|c|c|c|c|c|}
\hline No & $\begin{array}{c}\text { AREA } \\
\mu \mathrm{m}^{2}\end{array}$ & $\begin{array}{c}\text { PERIMETER } \\
\mu \mathrm{m}\end{array}$ & $\begin{array}{c}\text { MIND } \\
\mu \mathrm{m}\end{array}$ & $\begin{array}{l}\text { MAXD } \\
\mu \mathrm{m}\end{array}$ & $\mathrm{EF}$ & RF \\
\hline 1 & 94.11 & 38.57 & 9.34 & 13.55 & 0.69 & 0.95 \\
\hline 2 & 68.35 & 34.69 & 6.41 & 13.78 & 0.47 & 0.99 \\
\hline 3 & 68.23 & 35.33 & 6.63 & 14.52 & 0.46 & 0.9 \\
\hline 4 & 67.82 & 32.57 & 7.57 & 12.18 & 0.62 & 0.94 \\
\hline 5 & 60.38 & 30.04 & 8.25 & 10.37 & 0.80 & 0.90 \\
\hline
\end{tabular}

\begin{tabular}{|c|c|c|c|c|c|c|}
\hline No & $\begin{array}{l}\text { AREA } \\
\mu \mathrm{m}^{2}\end{array}$ & $\begin{array}{l}\text { PERIMETER } \\
\mu \mathrm{m}\end{array}$ & $\begin{array}{l}\text { MIND } \\
\mu \mathrm{m}\end{array}$ & $\begin{array}{l}\text { MAXD } \\
\mu \mathrm{m}\end{array}$ & $\mathrm{EF}$ & $\mathrm{RF}$ \\
\hline 1 & 18.32 & 17.18 & 3.98 & 6.44 & 0.62 & 0.91 \\
\hline 2 & 13.21 & 15.39 & 3.03 & 6.17 & 0.49 & 0.90 \\
\hline 3 & 14.52 & 14.76 & 3.83 & 5.35 & 0.72 & 0.9 \\
\hline 4 & 17.01 & 16.63 & 3.62 & 6.49 & 0.56 & 0.92 \\
\hline 5 & 20.46 & 21.89 & 3.04 & 9.47 & 0.32 & 0.90 \\
\hline 6 & 17.61 & 18.70 & 3.28 & 7.93 & 0.41 & 0.86 \\
\hline 7 & 23.08 & 20.82 & 3.73 & 8.52 & 0.44 & 0.92 \\
\hline
\end{tabular}

Table 3. Mean value and standard deviation of the nuclear parameters of the peripheral area of basaloid cell cutaneous neoplasms.

\begin{tabular}{|l|c|c|c|c|c|c|c|c|c|c|}
\hline $\begin{array}{l}\text { Nuclear } \\
\text { parameter }\end{array}$ & \multicolumn{2}{|c|}{ Scl BCC } & \multicolumn{2}{c}{ Nod BCC } & \multicolumn{2}{c|}{ Sup BCC } & \multicolumn{3}{c|}{ TB } & \multicolumn{3}{c|}{ TE } \\
\hline Mean & SD & Mean & SD & Mean & SD & Mean & SD & Mean & SD \\
\hline area $\left(\mu \mathrm{m}^{2}\right)$ & 45.54 & 15.16 & 50.05 & 15.29 & 43.05 & 12.48 & 38.30 & 10.16 & 30.93 & 9.33 \\
\hline perimeter $(\mu \mathrm{m})$ & 26.91 & 4.92 & 28.63 & 4.71 & 26.50 & 4.27 & 24.60 & 3.71 & 22.43 & 3.69 \\
\hline um diameter $(\mu \mathrm{m})$ & 6.16 & 1.21 & 6.32 & 1.13 & 5.71 & 0.98 & 5.66 & 0.86 & 4.94 & 0.84 \\
\hline um diameter $(\mu \mathrm{m})$ & 9.93 & 2.11 & 10.70 & 2.09 & 10.07 & 1.97 & 9.11 & 1.67 & 8.49 & 1.66 \\
\hline factor & 0.64 & 0.13 & 0.61 & 0.13 & 0.59 & 0.13 & 0.64 & 0.13 & 0.60 & 0.13 \\
\hline rity factor & 0.93 & 0.04 & 0.93 & 0.04 & 0.93 & 0.04 & 0.93 & 0.04 & 0.92 & 0.04 \\
\hline
\end{tabular}

Mean value \& yellow boxes $=\mathrm{p}<0.05$ of Scl BCC, Nod BCC, and Sup BCC vs. TE; SD value \& yellow boxes $=\mathrm{p}<$ 0.05 of Scl BCC vs. TB and of Nod BCC vs. TB and TE. Mann-Whitney U test. Other statistical differences are not shown. 